\title{
Lengthening of Femur by Combined Osteosynthesis: A Case Report
}

\section{Sergey S Leonchuk*}

Leonchuk SS, Russian Ilizarov Scientific Center for Restorative Traumatology and Orthopedics, Kurgan, Russia

${ }^{*}$ Corresponding author: Sergey S. Leonchuk, MD, head of the 6th orthopaedic department, Russian Ilizarov Scientific Center for Restorative Traumatology and Orthopedics, 6, M. Ulianova str., 640014, Kurgan, Russia, E-mail: leon4yk@mail.ru

Received date: February 18, 2017; Accepted date: March 20, 2017; Published date: March 27, 2017

Copyright: (c) 2017 Leonchuk SS. This is an open-access article distributed under the terms of the Creative Commons Attribution License, which permits unrestricted use, distribution, and reproduction in any medium, provided the original author and source are credited.

Citation: Leonchuk SS. Lengthening of Femur by Combined Osteosynthesis: A Case Report. Med Clin Rev. 2017, 3:1.

\section{Abstract}

Femur lengthening for correction of limb length discrepancy in a child with neurological defect (hemiparesis) was showed in the paper. In this case we used distraction osteosynthesis method by llizarov (external fixator) with elastic stable intramedullary nailing (ESIN) method. Lengthening rate was $0.95 \mathrm{~mm} /$ day (total $3.5 \mathrm{~cm}$ ), healing index was 34 days $/ \mathrm{cm}$. After 6 month of our treatment patient was satisfied for result and had initial Range of Motion (ROM) of hip and knee joints. Currently we are continuing our way of combined bone lengthening in patients with neurological defects in research project and recommend this plan.

Keywords: Femur; Lengthening; Ilizarov; External fixator; Intramedullary nailing

\section{Introduction}

The llizarov distraction osteosynthesis method is the best introducing for orthopaedic correction of axial deformities and limb length discrepancies [1]. Nowadays the problem of length discrepancies is solved by llizarov original device, different hexapod external fixators, lengthening over an intramedullary nail or epiphysiodesis contralateral extremity [2-5]. Unfortunately, in practice you can meet a lot of complications such as infections, longer period of fixator treatment, nonunion of bone, contractures of joints, and fractures after frame removal [6-8]. For example, according to Kocaoglu et al. [9] complications in treatment of patients by lengthening over an intramedullary nail occurred in $38 \%$ segments. In some colleagues papers period of external fixation treatment was noted more than 400 days with healing index until 62.7 days $/ \mathrm{cm}$ [10]. The ESIN is a mini-invasive intramedullary osteosynthesis method in association with the llizarov external fixator for limb lengthening is showed reducing a bone regenerate healing time and external fixation treatment period [11]. In this article the example of our approach in question of bone lengthening was presented.

\section{Case Presentation and Technical Report}

Patient X, 16 years old, female, entered in our department with complaints of a shortening of left lower extremity, backache after walking. There was patient with left-sided mixed hemiparesis (cerebral palsy) (Figure 1).

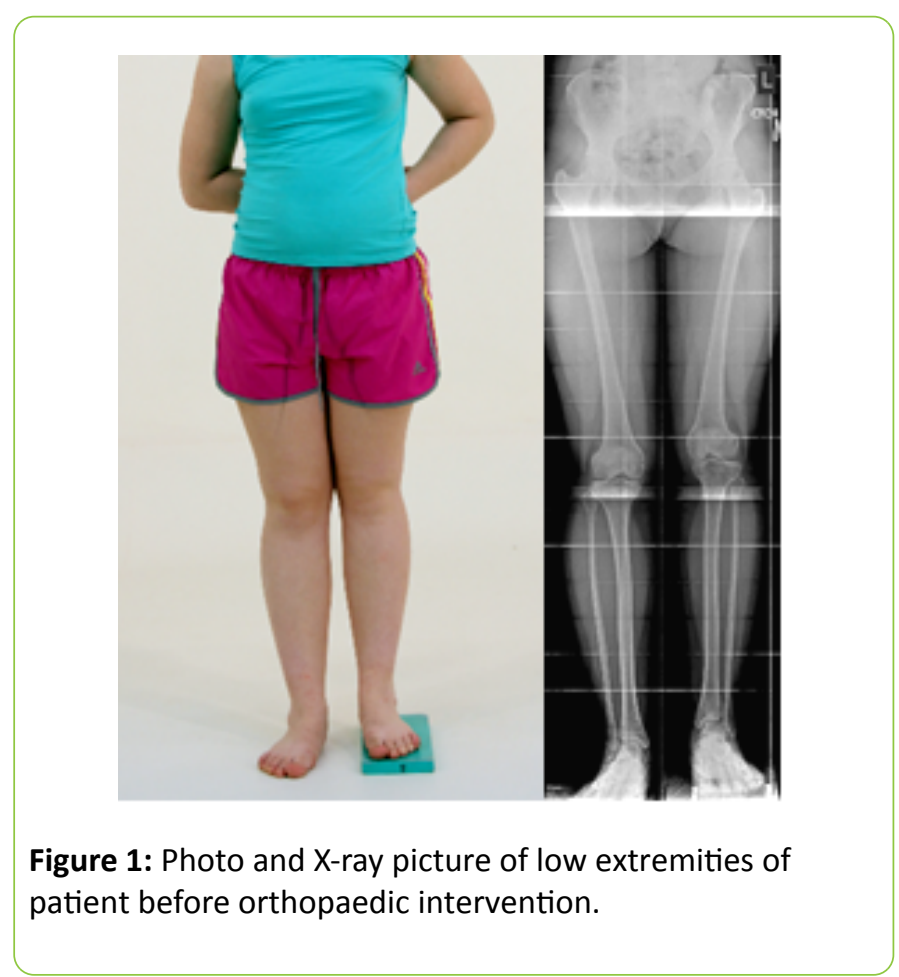

In 2011 she received surgical treatment on the left hip joint in the St. Petersburg clinic (about subluxation in hip joint). During a growth of the child, parents began to notice a shortening of the left leg. Child was examined clinically and by $X$-ray. She had shortening of femur in $3.5 \mathrm{~cm}$, low range of rotational motion in hip joint (external-internal rotation motion was 20|0|20) and full ROM in knee and ankle joints. Changes related to motor function (ambulation) were evaluated according to the Gillette Functional Assessment Questionnaire (FAQ) [12]. We used video recordings to assess patient's gait (ability to walk independently with or without 
walking aids). Recordings were made using two simultaneous cameras positioned in orthogonal projections.

Operative orthopaedic intervention started in placement Ilizarov original frame with universal joints (hinges). Then we performed percutaneous osteotomy in distal metaphysis zone of the femur. A $1.5 \mathrm{~cm}$ incision in the metaphyseal area was made on each side. The ESIN was inserted in a retrograde route from distal metaphysis for elastic and resistant condition of the bone during healing time (using external fixator). We placed 2 nail $(2.5 \mathrm{~mm})$ in an oblique direction after making holes through cortical by awl. Maximal curve of nails was located in level of future regenerate. The extraosseous $5 \mathrm{~mm}$ ends of the nails were curved over $90^{\circ}$.

Distraction period by Ilizarov device started from 5th day from operation date with X-ray control in each 10 days (Figure 2a). Patient was allowed to walk with gradually increasing weight-bearing on this extremity and with crutches. Lengthening rate was $0.95 \mathrm{~mm} /$ day. Duration of lengthening period was 37 days (8.75\% of initial bone length).

After our treatment length of the lower limbs was aligned (Figure 2b). llizarov frame was removed if 3 of 4 cortices could be seen by $\mathrm{X}$-ray pictures ( $\mathrm{AP}$ and $\mathrm{ML}$ ) and performed after clinical test. During distraction period patient was observed each day in our department by physiotherapist. Period of fixation by the llizarov frame was 82 days and healing index was 34 days $/ \mathrm{cm}$. There were no complications during our treatment.

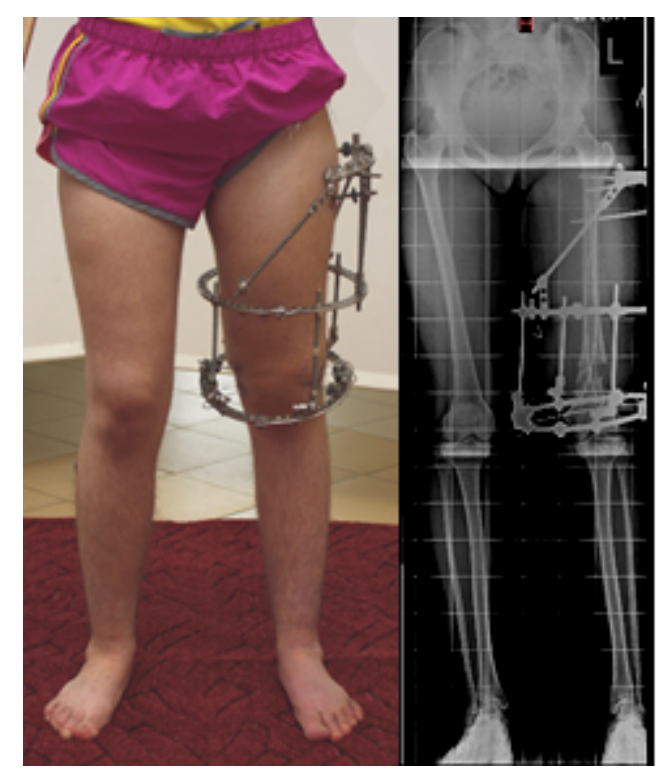

Figure 2a: Photo and X-ray pictures during llizarov frame treatment: during period of distraction.

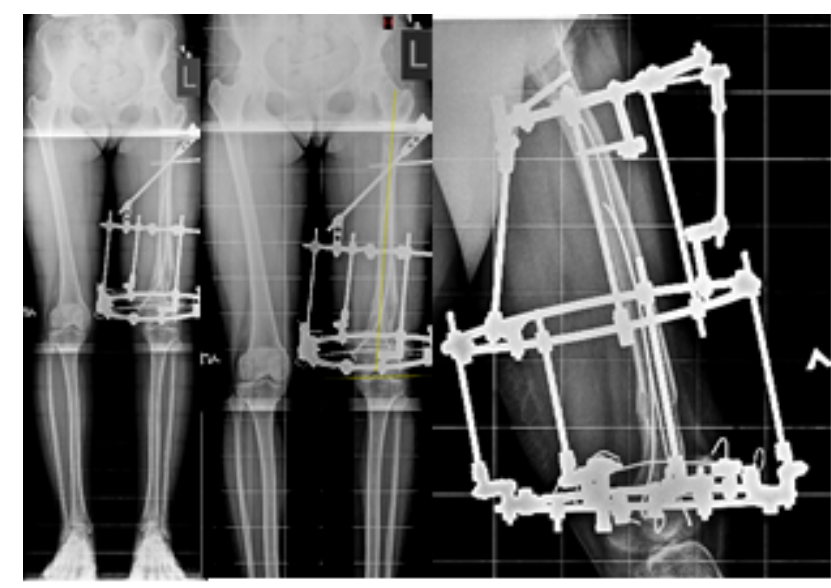

Figure 2b: Photo and X-ray pictures during Ilizarov frame treatment: before removing the llizarov frame.

After removal of the llizarov frame, patients left extremity was immobilized with a plaster bandage from the upper part of femur to ankle joint with fixation of knee joint during 6 weeks. Patient was allowed to walk with gradually increasing weight-bearing on this extremity with or without crutches. After removal of the plaster bandage patient was getting restorative treatment in the domiciliary clinic including physiotherapy and restoration of the range of motions of hip and knee joints, swimming pool, and limb immobilization with an orthosis (knee and ankle) for 6 months for the night. Amplitude of motions of interested joints (hip, knee) was restored up to initial one in 4 weeks after the beginning of the active exercises.

In 6 month follow-up patient was satisfied for result for result and had initial Range of Motion (ROM) of hip and knee joints (Figure 3). According to data received from the Gillette FAQ survey impairing of motor functions was not reported.

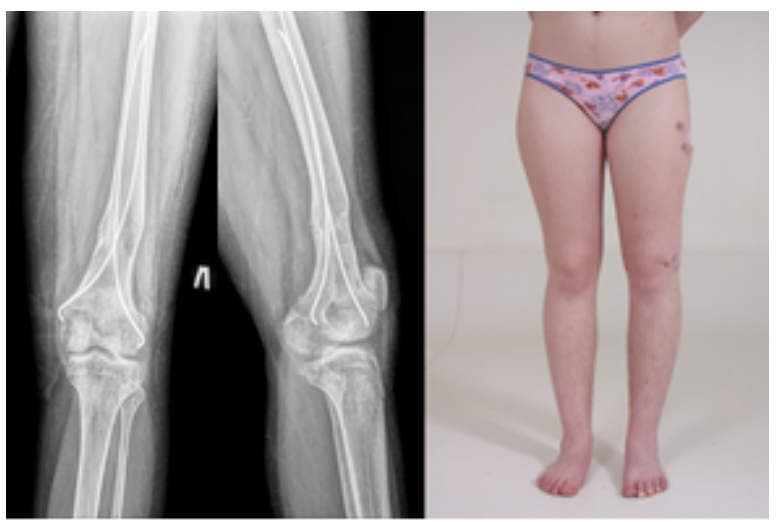

Figure 3: Photo and X-ray pictures of low extremities, in $6^{\text {th }}$ month follow-up.

Applying the combined methods of osteosynthesis demonstrated a considerably lower level of healing index (34.0 days $/ \mathrm{cm}$ ) than the results of our colleagues studies: Donnan et al. [8] healing index was noted 54 days/cm, Aktuglu et al. [10] - 
62,8 days/cm, Dammerer et al. [13]-57 days/cm, Blondel et al. [14]-38.2 days $/ \mathrm{cm}$. Absence of infections complications, secondary fragment displacement during correction and no deformity at the osteotomy after frame removal showed the advantages of this combined approach.

\section{Conclusion}

Therefore, combined osteosynthesis of the bone by external llizarov frame and ESIN in management of limb length discrepancy and adherence to the methodical principles of this methods and rational management in postoperative period allow reducing external fixator time, preventing of possible complications and achieving to the desired result of treatment.

\section{Conflict of Interest}

There are no conflicts of interest.

\section{Consent}

The patient has provided informed consent for the case report to be published.

\section{Authors' Contributions}

Leonchuk SS is the sole contributor of the submission and has approved the final manuscript.

\section{References}

1. Ilizarov GA (1990) Clinical application of the tension-stress effect for limb lengthening. Clin Orthop Relat Res 250: 8-26.

2. Stanitski DF, Bullard M, Armstrong P, Stanitski CL (1995) Result of femoral lengthening using the Ilizarov technique. J Pediatr Orthop 15: 224-231.

3. Baumgart R, Betz A, Schweiberer L (1997) A fully implantable motorized intramedullary nail for limb lengthening and bone transport. Clin Orthop Relat Res 343: 135-143.
4. Kristiansen LP, Steen H, Reikeras O (2006) No difference in tibial lengthening index by use of Taylor spatial frame or llizarov external fixator. Acta Orthop 77: 772-777.

5. Stevens P (2006) Guided growth: 1933 to the present. Strateg Trauma Limb Reconstr 1: 29-35.

6. Paley D (1990) Problems, obstacles, and complications of limb lengthening by the Ilizarov technique. Clin Orthop Relat Res 250: 81-104.

7. Ilharreborde B, Gaumetou E, Souchet P, Fitoussi F, Presedo A, et al. (2012) Efficacy and late complications of percutaneous epiphysiodesis with transphyseal screws. J Bone Joint Surg Br 94: 270-275.

8. Donnan LT, Gomes B, Donnan A, Harris C, Torode I, et al. (2016) Ilizarov tibial lengthening in the skeletally immature patient. Bone Joint J 98-B: 1276-1282.

9. Kocaoglu M, Eralp L, Kilicoglu O, Burc H, Cakmak M (2004) Complications encountered during lengthening over an intramedullary nail. J Bone Joint Surg Am 86-A: 2406-2411.

10. Aktuglu K, Gunay H, Alakbarov J (2016) Monofocal bone transport technique for bone defects greater than $5 \mathrm{~cm}$ in tibia: our experience in a case series of 24 patients. Injury 47: 40-46.

11. Popkov D, Journeau P, Popkov A, Haumont T, Lascombes $P$ (2010) Ollier's disease limb lenghtening: should intramedullary nailing be combined with circular external fixation? Orthop Traumatol Surg Res 96: 348-353.

12. Novacheck TF, Stout JL, Tervo R (2000) Reliability and validity of the Gillette Functional Assessment Questionnaire as an outcome measure in children with walking disabilities. J Pediatr Orthop 20: 75-81.

13. Dammerer D, Kirschbichler K, Donnan L, Kaufmann G, Krismer $M$, et al. (2011) Clinical value of the Taylor Spatial Frame: a comparison with the Ilizarov and Orthofix fixators. Journal of Children's Orthopaedics 5: 343-349.

14. Blondel B, Launay F, Glard Y, Jacopin S, Jouve JL, et al. (2009) Limb lengthening and deformity correction in children using hexapodal external fixation: Preliminary results for 36 cases. Orthop Traumatol Surg Res 95: 425-430. 